\title{
8
}

\section{im partilm} [Recensão a] Jorge Ferreira e Lucilia de Almeida Neves Delgado (org.), O Brasil
republicano, 4 volumes

\author{
Autor(es): $\quad$ Nunes, João Paulo Avelãs
}

Publicado por: $\begin{aligned} & \text { Instituto de História Económica e Social; Imprensa da Universidade de } \\ & \text { Coimbra }\end{aligned}$

URL

persistente:

URI:http://hdl.handle.net/10316.2/44513

DOI: $\quad$ DOI:https://doi.org/10.14195/0870-4147_37_21

Accessed : $\quad$ 26-Apr-2023 11:55:47

A navegação consulta e descarregamento dos títulos inseridos nas Bibliotecas Digitais UC Digitalis, UC Pombalina e UC Impactum, pressupõem a aceitação plena e sem reservas dos Termos e Condições de Uso destas Bibliotecas Digitais, disponíveis em https://digitalis.uc.pt/pt-pt/termos.

Conforme exposto nos referidos Termos e Condições de Uso, o descarregamento de títulos de acesso restrito requer uma licença válida de autorização devendo o utilizador aceder ao(s) documento(s) a partir de um endereço de IP da instituição detentora da supramencionada licença.

Ao utilizador é apenas permitido o descarregamento para uso pessoal, pelo que o emprego do(s) título(s) descarregado(s) para outro fim, designadamente comercial, carece de autorização do respetivo autor ou editor da obra.

Na medida em que todas as obras da UC Digitalis se encontram protegidas pelo Código do Direito de Autor e Direitos Conexos e demais legislação aplicável, toda a cópia, parcial ou total, deste documento, nos casos em que é legalmente admitida, deverá conter ou fazer-se acompanhar por este aviso. 


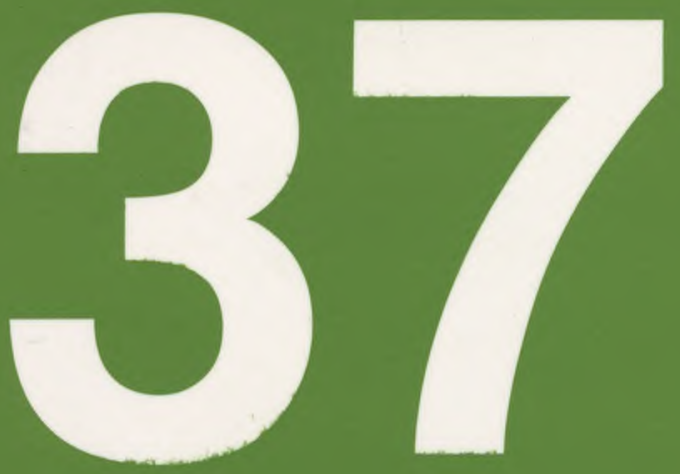

Revista Portuguesa de História

Faculdade de Letras da Universidade de Coimbra Instituto de Historia Econónica e Samial

Coimbra 05 
Revista Portuguesa de Historia

t. XXXVII (2005)

pp. $461-466$

\section{Jorge Ferreira e Lucilia de Almeida Neves Delgado (org.), $O$ Brasil republicano, 4 volumes, Rio de Janeiro, Editora Civilização Brasileira, 2003,1686 p.}

João Paulo Avelãs Nunes FLUC e CEIS20 da UC

Sob a direcção científica de Jorge Ferreira, da Universidade Federal Fluminense, e de Lucilia Delgado, da Pontifícia Universidade Católica de Minas Gerais, a Editora Civilização Brasileira publicou, no final de 2003,0Brasil republicano. Trata-se de urna obra colectiva que procura analisar a evolução daquele grande país latino-americano desde a instauração do regime republicano, em 1889, até aos nossos dias. Recorrendo a pressupostos epistemológicos, conceitos teóricos e metodologias típicos da "historia nova" e de outras ciências ou tecnologias sociais - direito constitucional e economia, sociologia e antropologia -, visa-se, ainda, contextualizar as realizações e os bloqueios da sociedade brasileira no início do século XXI.

Nas palavras dos organizadores, "os interpretações relativas à história do Brasil republicano têm, na maior parte das vezes, destacado uma questão recorrente: a de que a construção e consolidação da cidadania e da democracia são, simultaneamente, dilema e desafio que prepassam o cotidiano nacional brasileiro. Dilema, pois a herança do passado colonial/patrimonial persiste sob diferentes formas e graus ao longo da trajetória republicana, reproduzindo manifestações de práticas autoritárias, tanto na esfera privada quanto na pública. 
Desafio, pois a construção da democracia tem encontrado inúmeros focos de resistência que se manifestaram sob diferentes formas de comportamento político autoritário, destacando-se os periodos políticos ditatoriais, tanto o do Estado Novo quanto o do regime militar, além das antigas, mas ainda usuais, práticas de mandonismo local, que teimam em persistir, mesmo que no alvorecer de um novo milénio possam parecer ultrapassadas." (vol. 1, p. 7)

Fruto da conjugação de colaborações de diversos investigadores, provenientes de universidades e fundações de vários Estados da Federação, O Brasil republicano aborda temáticas de história político-institucional, económico-social e ideológico-cultural. Para além de privilegiarem o estudo de documentação oral e de textos de natureza memorialística, alguns dos artigos sobre "história do tempo presente" surgem como menos objectivantes, apresentando níveis significativos de "contaminação do discurso científico" por vectores ideológicos redutores ou maniqueístas.

Estruturada em 4 volumes, a obra em apreço propõe leituras complexificantes e actualizadas do século XX brasileiro. Consideram-se, nomeadamente, as modalidades de organização política dos grupos sociais dominantes e as funções desempenhadas pelas Forças Armadas; as características e atitudes das "classes populares" urbanas e rurais, bem como as formas de integração das sucessivas vagas de imigrantes. Abordaram-se as ligações entre as várias correntes nacionalistas e a orientação da política externa brasileira; a influência europeia ou norte-americana junto das "elites intelectuais canarinhas" e os processos de afirmação de diversas modalidades de cultura popular - ou de massas - de matriz citadina.

A generalidade da documentação impressa e da bibliografia citada é de origem brasileira, situação provavelmente associada à limitada atenção dedicada por investigadores estrangeiros ou à escassa disponibilidade da "historiografia canarinha" sobre a época contemporânea para estabelecer ligações internacionais e elementos de comparação com outros países. Tal como as notas de rodapé, também as listagens de documentação e bibliografia encontram-se no final dos artigos ou de cada um dos volumes. Deparamo-nos, igualmente, com blocos de ilustrações legendadas e com inventários de filmografia relevante para o conhecimento dos subperíodos delimitados.

Com o título "O tempo do liberalismo excludente - da proclamação da República à Revolução de 1930", o vol. 1 procura caracterizar a etapa que decorreu entre a "Proclamação de 15 de Novembro de 1889" e o início da fase de transição que viabilizou a instauração do Estado Novo de Getúlio Vargas. Analisam-se o monopolizar do sistema político pelas elites estaduais ou municipais - o "coronelismo" - e os elevados níveis de violência institucional vigentes; as tensões entre agentes de modernização e de conservadorismo no âmbito das "classes 
dirigentes". Observam-se os movimentos tradicionalistas de natureza político-religiosa ("Juazeiro, Canudos e Contestado") e a emergência do "tenentismo", expressão máxima do "radicalismo progressista" de origem político-militar; a estruturação do "movimento operário" e as implicações socioculturais dos projectos de "renovação urbanística" ou de controlo dos "problemas de saúde pública".

Designado "O tempo do nacional-estatismo - do início da década de 1930 ao apogeu do Estado Novo", o vol. 2 estuda os anos de 1930 e a primeira metade da década de quarenta. Face à crise do "modelo de exportação de matérias-primas" e do "Estado liberal-conservador", perante a hipertrofia dos poderes estaduais e a crescente intervenção política das "classes populares", parte significativa das elites brasileiras assumiu as vantagens de concretizar uma "estratégia autoritária" de "regeneração e engrandecimento nacional". Depois de consolidada a "solução ditatorial", o Executivo federal passou a tutelar as instâncias regionais e a dinamizar um projecto de "fomento industrial". Foram perseguidos, quer as oposições de esquerda e de extrema-direita, quer o "movimento sindical livre", adoptando-se, ainda, modalidades de enquadramento estatal dos trabalhadores urbanos.

Organizadas de acordo com os princípios da "democracia-cristã conservadora", a Igreja e a "acção católica" (o essencial dos sacerdotes e leigos) passaram a integrar o universo ideológico e institucional do Estado Novo. Primeiramente ligada ao regime, a Acção Integralista Brasileira acabou por manifestar "intenções revolucionárias" que legitimaram a repressão de que foi alvo. Destino idêntico conheceram o Partido Comunista Brasileiro e a Aliança Nacional Libertadora quando optaram pela "via armada" de transformação política. Limitados pelas sequelas da crise económica internacional e pela ditadura, pelos "baixos níveis de mobilização dos trabalhadores" e pelo modelo estalinista, os anseios de "modernização e justiça social" encontraram no "putshismo tenentista" - sobretudo em Luís Carlos Prestes - o parceiro estratégico natural.

Tal como em outros regimes de natureza autoritária ou totalitária, a ditadura chefiada por Getúlio Vargas estruturou organismos responsáveis pela gestão coordenada da "propaganda de Estado" - antes de mais o Departamento de Imprensa e Propaganda - e de repressão (censura, polícia política e tribunais especiais, locais de interrogatório e prisões). Depois de uma primeira fase em que ensaiou uma postura de "neutralidade flexível" relativamente às grandes potências demoliberais e fascistas, o Executivo brasileiro negociou com os EUA e o Reino Unido, sobretudo com Washington, os termos da participação na Segunda Guerra Mundial ao lado dos Aliados. Contribuiu, assim, para frustrar quaisquer hipóteses de criação de um bloco de países com "Governos de ordem" que envolveria a Santa Sé, nações da Europa do Sul e da América Latina. 
O período da história brasileira iniciado com a "Crise de 1929" e encerrado com o conflito de 1939-1945 teria assistido, igualmente, à lenta generalização de fenómenos culturais criados ou adoptados pelas camadas mais segregadas e desfavorecidas da população. O samba e o carvaval, o candomblé e a capoeira, o futebol e a "libertação do corpo", os imaginários nordestino e "indígena" foram incorporados na cultura de massas e na cultura erudita à escala nacional. Por um lado, a evolução em causa facilitou a afirmação individual e colectiva dos cidadãos de origem índia, negra e "sertaneja"; em sentido inverso, viabilizou novas lógicas de dominação social e reprodução das desigualdades, de controlo e mobilização (ou manipualção) política.

Tanto ou mais do que em outros países, o "modernismo cultural" integrou, no Brasil das décadas de 1930 e 1940, elementos diversos e aparentemente contraditórios. Defenderam-se as vantagens da "matriz europeia e norte-americana" ou da "especificidade lusotropical"; a superioridade das sociedades onde predominava a "raça branca" ou onde vigorava a "mestiçagem". Utilizaram-se referências "cosmopolitas" ou "folclóricas" (regionalistas e étnico-religiosas); mundividências intemacionalistas ou nacionalistas. Apoiaram-se regimes fascistas ou autoritários de direita, demoliberais ou democráticos, socialistas ou comunistas. Existiu colaboração com e resistência ao Estado Novo; repressão, tolerância ou patrocínio por parte da ditadura chefiada por Getúlio Vargas.

Quanto ao vol. 3 ("O tempo da experiência democrática - da democracia de 1945 ao golpe militar de 1964”), aborda a desagregação, no essencial pacífica, do Estado Novo no imediato pós-guerra e a transformação do "getulismo" numa realidade político-ideológica diferente das soluções vigentes desde 1930 e 1937; a instauração e as dificuldades de normalização do regime demoliberal ou democrático; os factores próprios e alheios que tomaram possível a consolidação da Ditadura Militar no seguimento do Golpe de 1 de Abril de 1964. Fortemente implantado junto dos trabalhadores urbanos, o "Movimento Queremista" simbolizou a "originalidade da transição brasileira". Exigiu, em simultâneo, a instauração da democracia e a continuidade de Getúlio Vargas como Presidente da República, o fim do "Estado corporativo" e a permanência das "regalias sociais" embrionárias introduzidas na segunda metade dos anos 1930.

Beneficiando de uma situação de crescimento económico prolongado no plano internacional, os vários Executivos brasileiros teriam adoptado políticas económico-financeiras nacionalistas e proteccionistas; industrialistas mas viabilizadoras da permanência da "oligarquia terratenente", ligada, quer à ruralidade arcaica, quer à moderna "agroindústria". Coincidiram, quer iniciativas empresariais - públicas e privadas - de grande escala e sofisticação tecnológica, quer altos níveis de corrupção e de desperdício de recursos ou potencialidades 
(sistemas de produção e distribuição de energia, acesso à água para consumo doméstico e industrial ou agrícola, transporte ferroviário e aproveitamento sustentável da floresta, etc.); por um lado medidas de limitação do "domínio estrangeiro sobre a economia nacional", por outro balanças de pagamentos largamente deficitárias e forte endividamento externo.

Somente em 1963, já numa fase terminal da conturbada presidência de João Goulart, o Plano Trienal, apresentado por Celso Furtado (Ministro Extraordinário do Planejamento), surgiu como alternativa consistente aos bloqueios detectados: "As metas principais eram as de combater a inflação sem comprometer o desenvolvimento económico e, em um passo seguinte, implementar reformas, sobretudo no aparelho administrativo, no sistema bancário, na estrutura fiscal e, em particular, na estrutura agrária [...]. Pela primeira vez o país enfrentaria um processo inflacionário sem apelar, unicamente, para o equilibrio financeiro, com medidas estritamente ortodoxas. Sem deixar de recorrer ao receituário monetarista. Furtado adoptou também a estratégia estruturalista para solucionar os problemas que o país enfrentava. Com a inflação controlada, a reforma agrária daria impulso a um ciclo de crescimento. Ao mesmo tempo, o Plano procurava valorizar o capital humano, com investimentos na educação, saúde pública, pesquisa científica e habitação. ” (vol. 3, p. 364)

Em termos sociais, verificou-se o reforço, tanto do empenhamento sindical e político, como dos "direitos laborais" dos assalariados urbanos. A citada evolução decorreu da capacidade de luta dos trabalhadores, da "intervenção reformista" dos poderes estaduais e federal, da lógica de gestão adoptada por muitas das novas empresas industriais e de serviços. Mesmo nas zonas rurais, tradicionalmente passivas e conservadoras, deu-se a emergência das Ligas Camponesas e de sindicatos de "proletários agrícolas". Reivindicaram o fim da arbitrariedade e da violência por parte dos grandes proprietários, o aplicar da "legislação trabalhista" ao sector agropecuário e florestal, a concretização de projectos de "reforma agrária e industrialização".

Ancorado em grandes oiganizações partidárias de âmbito federal - União Democrática Nacional, Partido Social Democrático e Partido Trabalhista Brasileiro -, o sistema político brasileiro apresentou, de 1945 a 1964, um elevado grau de instabilidade. Resultou esse traço de identidade dê múltiplos factores, com destaque para as acentuadas desigualdades sociais e a ilegalização do Partido Comunista Brasileiro (logo em Maio de 1947), as dificuldades económico-financeiras e as "ingerências estrangeiras", as cisões no interior dos partidos políticos e as rivalidades entre os Estados da Federação, a politização das Forças Armadas e a vinculação ideológica explícita dos mass media, a inconstância de muitas lideranças e a mundividência providencialista de amplos segmentos da população. 
Depois de sobreviver às "crises da República" de 1954,1955 e 1961, o sistema demoliberal ou democrático instaurado em 1945 foi derrubado pelo Golpe militar e civil de Abril de 1964. O novo tipo de ditadura explicar-se-ia pela fobia da Revolução Cubana nas Administrações norte-americanas e nas "elites conservadoras canarinhas"; pela radicalização de parcelas significativas da sociedade brasileira - à direita e à esquerda do espectro político - e pelas incoerências dos defensores da "legalidade constitucional". Diversos investigadores salientam, entretanto, a centralidade da "intervenção golpista" dos Instituto Brasileiro de Pesquisas Económicas e Sociais, Instituto Brasileiro de Acção Democrática, Acção Democrática Parlamentar e Escola Superior de Guerra, esta última com origem no National War College (Washington).

Intitulado "O tempo da ditadura - regime militar e movimentos sociais em fins do século XX", o vol. 4 considera a ideologia fundadora e os principais mecanismos repressivos da Ditadura Militar (Doutrina de Segurança Nacional e serviços de informações, censura e propaganda, polícia política e "esquadrões da morte"); os movimentos de "guerrilha urbana ou rural" e a intervenção do "catolicismo progressista". Analisam-se, também, as etapas "monetarista" e "nacionalista" da governação económica e financeira, bem como as mutações da política externa; a luta pela hegemonia no âmbito cultural e a afirmação de um novo sindicalismo oposicionista; o processo de "abertura política" e a permanência de bloqueios estruturais nos planos da "questão agrária" e do relacionamento internacional.

A encerrar o presente esboço de apreciação crítica, elencam-se algumas eventuais insuficiências de $O$ Brasil Republicano. Justificar-se-ia uma caracterização mais exaustiva do Estado Novo e da Ditadura Militar, em si mesmos e por comparação com outros regimes similares; dos vectores nucleares de funcionamento dos sistemas liberal-conservador e demoliberal ou democrático até 1930 e de 1945 a 1964. Interessaria, ainda, conhecer melhor o "fenómeno Getúlio Vargas"; a intervenção dos segmentos dominantes da Igreja e da "aç̧ão católica" - distintos do "catolicismo progressista" - ao longo do século XX; o "braço civil" do regime militar de 1964 à década de 1980. 